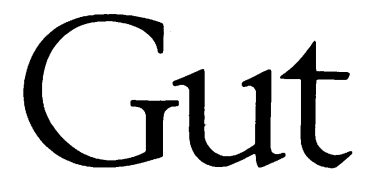

Leading article

\title{
Vasodilatation associated with hepatocellular disease: relation to functional organ failure
}

The patient with hepatocellular disease shows marked vasodilatation, with opening of arteriovenous shunts in almost all vascular territories including the skin, muscle, kidneys, lungs, portal venous system and even the brain. These circulatory changes can be related to general tissue hypoxia, to functional renal and pulmonary failure, to portal venous hypertension and perhaps to cerebral oedema. The agents responsible remain unknown. Candidates include glucagon and prostaglandins: local tissue factors may contribute.

The hyperdynamic circulation found in patients with hepatocellular disease, particularly cirrhosis, is well known.' The effect of these circulatory changes, and particularly the profound vasodilatation has only recently been investigated in detail.

This paper provides an overview of the general vasodilatory state and its effect on various organs. It also discusses the mechanisms and the various vasoactive substances that might be responsible.

\section{General circulatory changes}

In patients with hepatocellular failure, whether acute or chronic, the extremities are flushed, the pulses bounding, the cardiac output increased and the blood pressure low. Systemic vascular peripheral resistance is reduced as is the arteriovenous oxygen difference. Chronic heart failure rarely ensues. Vasomotor tone is decreased as shown by reduced vasoconstriction in response to mental exercise, the Valsalva manoeuvre and tilting from the horizontal to the vertical position. ${ }^{23}$ The circulation resembles that found with systemic arteriovenous fistulae. It may be that large numbers of normally present, but functionally inactive, arteriovenous anastomoses open up as a response to profound vasodilatation.

In patients with cirrhosis, whole body oxygen consumption is decreased and tissue oxidation is abnormal. ${ }^{+}$This has been related to the hyperdynamic circulation and to arteriovenous shunting. Thus, the vasodilator state of liver failure may contribute to general tissue hypoxia.

\section{Skin and muscle}

Blood flow is increased, particularly in the skin and to a lesser extent in muscle. ${ }^{5}$ Finger blood flow, which is largely that through the skin, is increased. ${ }^{6}$ Television microscopy has shown marked capillary dilatation in nail beds. ${ }^{7}$ Cutaneous spider naevi, so frequent in cirrhosis of the alcoholic, pulsate but their presence seems to bear little relationship to the increase in skin blood flow.

\section{Pulmonary changes}

About a third of patients with decompensated cirrhosis have reduced arterial oxygen saturation and are sometimes cyanosed. ${ }^{8}$ This is probably caused by intrapulmonary shunting through microscopic arteriovenous fistulae.

Injection studies of the pulmonary artery in cirrhotic patients have shown marked arterial dilatation in fine peripheral branches of the pulmonary artery both within the respiratory parts of the lung and on the pleura where spider naevi are sometimes seen. ${ }^{9}$ Reduction in diffusing capacity is present without a restrictive ventilatory defect. This is probably the result of dilatation of small pulmonary blood vessels, a complication both of advanced cirrhosis and fulminant hepatic failure..$^{10}$ The pulmonary vasodilatation is associated with a low pulmonary vascular resistance. The dilatation is so marked that it is not further increased by exercise, ${ }^{11}$ and there is reduced pulmonary vasoconstriction in response to hypoxia. ${ }^{12}$ In cirrhosis, the hypoxaemia with intrapulmonary shunting and impaired lung perfusion has been termed the 'functional hepatopulmonary syndrome'. ${ }^{13}$

\section{Kidney}

The circulatory changes in the kidney of patients with hepatocellular failure are extremely complex. Abnormalities can be shown even before the development of ascites. In the late stages, the intrarenal circulation is so disturbed that functional renal failure develops (hepatorenal syndrome). Renal blood flow is reduced because of generalised vasodilatation and diversion of blood to other parts such as skin and muscle. Blood flow within the kidney is redistributed. Increased preglomerular vascular resistance and arteriovenous shunting divert blood away from the outer cortex to the inner cortex and medulla. In the urine, the vasoconstrictive metabolites of arachadonic acid (thromboxane A2) predominate over the vasodilator ones (prostaglandin E2). In the early stages, however, general vasodilatation results in increased vascular capacitance which is arteriolar, capillary and venous. Secondary compensatory stimulation of the humoral pressor (sympathetic) system attempts to maintain 
circulatory haemostasis in the presence of a tendency to hypotension. ${ }^{1+15}$ The importance of vasodilator substances in the pathogenesis of renal dysfunction in hepatic failure is supported by the improved renal function whch follows the infusion of a vasoconstrictor agent, 8-ornithin vasopressin in decompensated cirrhosis. ${ }^{16}$

\section{Brain}

There is little information on the cerebral circulation in patients with liver disease but no hepatic encephalopathy. In one study, mentally alert patients with cirrhosis showed an increase of cerebral blood flow and cerebral vascular resistance was reduced. ${ }^{17}$ These changes became more marked after portacaval shunt or in acute hepatic encephalopathy. Another report referred to unpublished work in which cerebral blood flow was said to be markedly increased in grade IV coma. ${ }^{18}$ The vasodilatation and increased cerebral blood flow taking place within the rigid cranial vault, would lead to an increased brain blood volume and a rise in intracranial pressure. This would be followed by papilloedema and cerebral oedema. This is the usual terminal event in patients dying in fulminant hepatic failure ${ }^{1819}$ although in the very late stages cerebral blood flow falls.

\section{Portal circulation}

It was thought that portal venous obstruction in a cirrhotic patient was followed by the development of portal-systemic collaterals which attempted to reduce the portal venous pressure. The portal venous system became congested and sluggish. This backward flow theory, however, proved false, as non-invasive Doppler-ultrasound measurements have shown increased flow in the portal vein of cirrhotic patients. ${ }^{20}$ Blood flow through the azygos system, which includes most of the superior portosystemic collaterals, is increased and is greater than can be explained by the rise in cardiac output alone. ${ }^{21}$ This indicates vasodilatation of the collateral circulation. Studies of the individual organs in the portal vascular territory confirm the vasodilatation. Thus, splenic blood flow is increased in cirrhotic patients. ${ }^{22}$ Red spots may be seen on the gastric antrum of patients with portal hypertension at endoscopy. These represent a congestive gastropathy due to capillary vascular ectasia. ${ }^{23}$ In the rat model of portal hypertension, gastric mucosal blood flow is increased and gastric vascular resistance decreased. There is an impaired acid secretory response to pentagastrin stimulation. ${ }^{24}$

\section{Discussion}

The patient with hepatocellular disease has a hyperdynamic circulation and seems to be in a state of generalised vasodilatation. This is independent of the cause of the liver disease and is present in both cirrhosis and in acute, fulminant liver failure ${ }^{25}$ and is proportional to the degree of hepatocellular failure. In cirrhosis the cardiac index and reduced systemic vascular resistance correlate with the Child's grade of liver failure. ${ }^{21}$ The hyperdynamic state is proportional to the functioning hepatic mass as determined by indocyanine green clearance. ${ }^{27}$ Limited observations show that some of the circulatory changes are relieved by liver transplantation. This is certainly true of the hepatopulmonary syndrome, ${ }^{1328}$ and the hepatorenal syndrome. ${ }^{29}$ The vasodilatation is so marked that in the lungs it reduces the vasoconstrictor effects of hypoxia ${ }^{12}$ and ameliorates arterial hypertension in the spontaneously hypertensive rat. ${ }^{30}$

The secondary events which follow the vasodilatation include stimulation of the sympathetic nervous system which becomes overactive in patients with chronic liver disease. ${ }^{31} 32$ The peripheral vasodilatation and splanchnic venous pooling reduce the effective blood volume so activating baroreceptors. This serves to counteract the tendency to arterial hypotension and probably contributes to renal hypoperfusion and to the development of the hepatorenal syndrome.

The nature of the vasodilators concerned remains speculative. They are likely to be multiple and the agent responsible for the hyperdynamic portal system of cirrhosis is probably not the same as that causing the systemic hyperdynamic state of fulminant liver failure. Most of the observations to determine their nature have been conducted on the rat model of portal hypertension (ligated portal vein or cirrhosis). In this model, the vasodilator responsible is presumably humoral for blood from portal hypertensive rats increases intestinal blood flow. Whatever its nature, the substance might be formed by the sick hepatocyte, fail to be inactivated by it or bypass it through intra- or extra-hepatic portal systemic shunts.

Ammonia and endotoxin reduce intestinal vascular resistance. In portal hypertensive rats, however, the administration of neomycin, which would reduce toxic substances produced by intestinal bacteria, fails to influence the portal hyperdynamic state. ${ }^{33}$ Any analogy to portal systemic encephalopathy therefore seems unlikely.

Gamma aminobutyric acid (GABA), a potent inhibitory neurotransmitter, is synthesised by the intestinal mucosa and by anaerobic bacteria in the gut. In advanced liver disease, hepatic clearance of GABA is impaired and thus might cause hypotension by small muscle relaxation. GABA could play a part in the circulatory changes of cirrhosis. ${ }^{34}$

Various gastrointestinal peptides such as VIP and substance $P$ have little effect on the portal circulation. ${ }^{35}$ Glucagon is a vasodilator and the plasma concentration increases in rats with portal hypertension..$^{35}$ In rats with a portacaval shunt, the plasma glucagon concentration rises as the portal venous flow increases and the portal circulation becomes hyperdynamic. ${ }^{36}$ Glucagon increases azygos blood flow in patients with cirrhosis, ${ }^{37}$ but with no effect on cardiac index or renal haemodynamics implying little effect on systemic vascular resistance. Glucagon is unlikely to be the sole vasodilator responsible.

Prostaglandins (PGE1, PGE2 and PG12) have vasodilatory actions and prostanoids are released into the portal vein in patients with chronic liver disease. ${ }^{38}$ In portal hypertensive rabbits, prostacyclin (PG12) is increased in the arterial blood and the splanchnic hyperaemia is ameliorated by indomethacin which blocks endogenous prostaglandin formation. ${ }^{39}$ In cirrhosis, circulation through the kidney depends on vasodilatory prostaglandins and their inhibition by indomethacin can have disastrous results. ${ }^{+0}$ It is possible, therefore, that prostaglandins play a part in the vasodilatation of hepatocellular disease.

Reduced sensitivity of the vasculature to endogenous vasoconstrictors must also be considered. In portal hypertensive rats, this is so for noradrenaline.$^{41}$ On the other hand, the portal venous system of the rat model of portal hypertension is hypersensitive to the vasoconstrictor action of 5-hydroxytryptamine, ${ }^{42}$ and ketanserin, a 5-hydroxytryptamine-2 inhibitor, decreases portal pressure in patients with cirrhosis. ${ }^{43}$ Complications, including portalsystemic encephalopathy, preclude its general use as a portal hypotensive drug. In patients with liver disease the vasodilatation and hyperdynamic state and particularly the arteriovenous shunting are harmful as they contribute to tissue hypoxaemia, to the development of oesophageal varices and probably to ascites formation, functional renal failure and cerebral oedema. The increase in portal venous blood flow can be regarded as beneficial as it increases that fraction of portal flow which overcomes the resistance of the cirrhotic liver to supply the sick hepatocyte. The increased cardiac output augments the delivery of oxygen to the tissues. 
When the vasodilatory factors have been identified it will become clear whether their role is harmful or beneficial. Improved prospects for medical control of portal hypertension and the treatment of fulminant liver failure will follow.

\section{SHEILA SHERLOCK}

Department of Surgery,

Royal Free Hospital,

London NW3 2QG

1 Murray JF, Sherlock S. Circulatory changes in chronic liver disease. Am $\mathcal{F}$ Med 1958; 24: 358-67.

2 Lunzer MR, Manghani KK, Newman SP, et al. Impaired cardiovascular responsiveness in liver disease. Lancet 1975; i: 382-5.

3 Lunzer $M$, Newman SP, Sherlock S. Skeletal muscle blood flow and neurovascular reactivity in liver disease. Gut 1973; 14: 354-9.

4 Moreau R, Lee SS, Soupison T, et al. Abnormal tissue oxygenation in patients with cirrhosis and liver failure. $\mathcal{f}$ Hepatol $1988 ; 7: 98-105$.

5 Martini GA. Über Fefässveranderungen der Haut bei Leberkranken. Z. Klin Med 1955; 153: 470-526.

6 Martini GA. Uber Fingernagelveranderungen bei Lebercirrhose als Folge Veranderter peripherer Durchblüting. Klin Wochenschr 1956; 34: 25-31.

7 Pirovino M, Linder R, Boss C, et al. Cutaneous spider naevi in liver cirrhosis: capillary, microscopical and hormonal investigations. Klin Wochenschr 1988; capillary, $298-302$.

8 Rodman T, Sobel M, Close HP. Arterial oxygen unsaturation and the ventilation perfusion defect of Laennec's cirrhosis. $N$ Engl f Med 1960; 263 ventilat

9 Berthelot P, Walker JG, Sherlock S, et al. Arterial changes in the lungs in cirrhosis of the liver-lung spider nevi. N Engl f Med 1966; 274: 291-8.

10 Williams A, Trewby P, Williams R. Structural alterations to the pulmonary circulation in fulminant hepatic failure. Gut 1979; 34: 447-53.

11 Agusti AGN, Roca J, Rodriguez-Roisin R, et al. Pulmonary hemodynamics and gas exchange during exercise in liver cirrhosis. Am Rev Respir Dis 1988; 138 $117-20$.

12 Rodriguez-Roisin R, Roca J, Agusti AGN, et al. Gas exchange and pulmonary vascular reactivity in patients with liver cirrhosis. Am Rev Respir Dis 1987 135: 1085-92.

13 Eriksson LS, Soderman C, Wahren J, et al. Is hypoxemia in cirrhotic patients due to a functional 'hepatopulmonary syndrome'? [Abstract]. $\mathcal{F}$ Hepatol due to a functir

14 Schrier RW, Caramelo C. Hemodynamics and hormonal alterations in hepatic cirrhosis in the kidney in liver disease. Epstein M, ed. 3rd edn. New York: Williams and Wilkins, 1988 .

15 Arroyo V, Bernardi M, Epstein M, et al. Pathophysiology of ascites and functional renal failure in cirrhosis. F Hepatol 1988; 6: 239-57.

$16 \mathrm{Lenz} \mathrm{K}$, Hortnagl H, Druml W, et al. Beneficial effect of 8-ornithin vasopressin on renal dysfunction in decompensated cirrhosis. Gut 1989; 30: 90-6.

17 Polli E, Porro GB, Maiolo AT. Cerebral metabolism after portacaval shun [Letter]. Lancet 1969; i: 153 .

18 Ede RJ, Gimson AES, Bihari D, et al. Controlled hyperventilation in the prevention of cerebral oedema in fulminant hepatic failure. 7 Hepatol 1986; 2: 43-51.

19 Ware AJ, D'Agostino AN, Combes B. Cerebral edema: a major complication of massive hepatic necrosis. Gastroenterology 1971; 61: 877-84.
20 Gaiani S, Bolondi L, Bassi SL, et al. Effect of a meal on portal hemodynamics in healthy humans and in patients with chronic liver disease. Hepatology 1989; 9: 815-9.

21 Braillon A, Cales P, Valla D, et al. Influence of the degree of liver failure on systemic and splanchnic haemodynamics and on response to propranolol in systemic and splanchnic haemodynamics and

22 Gitlin N, Grahame GR, Kreel L, et al. Splenic blood flow and resistance in patients with cirrhosis before and after portacaval anastomoses. Gastropatients with cirrhosis befor
enterology 1970; 59: 208-13.

23 Quintero E, Pique JM, Bombi JA, et al. Gastric mucosal vascular ectasia causing bleeding in cirrhosis. Gastroenterology 1987; 93: 1054-61.

24 Pique JM, Leung FW, Kitahora T, et al. Gastric mucosal blood flow and acid secretion in portal hypertensive rats. Gastroenterology 1988; 95: 727-33.

25 Hecker R, Sherlock S. Electrolyte and circulatory changes in terminal liver failure. Lancet 1956; ii: 1121-5.

26 Trewby PN, Williams R. Pathophysiology of hypotension in patients with fulminant liver failure. Gut 1977; 18: 1021-6.

27 Ito K, Ramirez-Schon G, Shah PM, et al. Functioning hepatic cell mass and the hyperdynamic state in cirrhosis. Surg Gynecol Obstet 1988; 167: 180-6.

28 Hagenah C, Sybrecht GW. Disturbances of respiration of patients before and after liver transplantation. Respiration 1987; 52: 290-7.

29 Wood RP, Ellis D, Starzl TE. The reversal of the hepatorenal syndrome in four pediatric patients following liver transplantation. Ann Surg 1987; 205: 415-9.

30 Polio J, Groszmann RJ, Reuben A, et al. Portal hypertension ameliorates arterial hypertension in spontaneously hypertensive rats. $\mathcal{F}$ Hepatol $1989 ; 8$ 294-301.

31 Bernadi M, Santini C, Trevisani F, et al. Renal function impairment induced by change in posture in patients with cirrhosis and ascites. Gut 1985; 26: 629-35.

32 Henriksen JH, Ring-Larsen H, Christensen NJ. Hepatic intestinal uptake and release of catecholamines in alcoholic cirrhosis. Evidence of enhanced hepatic intestinal sympathetic nervous activity. Gut 1987; 28 : 1627-42.

33 Blei AT. Conference - The pathophysiology and treatment of portal venous hypertension. Barcelona, 3-4 March, 1989.

34 Minuk GY, MacCannell KL. Is the hypotension of cirrhosis a GABA-mediated process? Hepatology 1988; 8: 73-7.

35 Benoit JN, Barrowman JA, Harper SL, et al. Role of humoral factors in the intestinal hyperemia associated with chronic portal hypertension. Am $\mathcal{J}$ Physiol 1984; 247: G486-93.

36 Kravetz D, Arderiu M, Bosch J, et al. Hyperglucagonemia and hyperkinetic circulation after portocaval shunt in the rat. Am F Physiol 1987; 252: G25761 .

37 Lee SS, Moreau R, Hadengue A, et al. Glucagon selectively increases splanchnic blood flow in patients with well-compensated cirrhosis. Hepatology $1988 ; 8: 1501-5$.

38 Wernze $\mathrm{H}$, Tittor W, Goeing $M$. Release of prostanoids into the portal and hepatic vein in patients with chronic liver disease. Hepatology 1986; 6: 911-6.

39 Sitzmann JV, Bulkley GB, Mitchell MC, et al. Role of prostacyclin in the splanchnic hyperemia contributing to portal hypertension. Ann Surg 1989; 209: 322-7.

40 Garella S, Matarese RA. Renal effects of prostaglandins and clinical adverse effects on non-steroidal anti-inflammatory agents. Medicine (Baltimore) 1986; 63: $165-81$.

41 Kiel JW, Pitts V, Benoit JN, et al. Reduced sensitivity to norepinephrine in portal hypertensive rats. Am $\mathcal{F}$ Physiol 1985; 248: G192-5.

42 Cummings SA, Groszmann RJ, Kaumann AJ. Hypersensitivity of mesenteric veins to 5-hydroxytryptamine and ketanserin induced reduction of portal pressure in portal hypertensive rats. Brf Pharmacol 1986; 89: 501-13.

43 Vorobioff J, Garcia-Tsao G, Grozmann R, et al. Long-term hemodynamic effects of ketanserin, a 5-hydroxytryptamine blocker, in portal hypertensive patients. Hepatology 1989; 9: 88-91. 